\title{
Failure mode transition in air-backed plates from near contact underwater explosions
}

\author{
Mark J. Riley ${ }^{\mathrm{a}, *}$, Geoffrey T. Paulgaard ${ }^{\mathrm{b}}$, Julian J. Lee ${ }^{\mathrm{c}}$ and Malcolm J. Smith ${ }^{\mathrm{a}}$ \\ ${ }^{a}$ Defence Research and Development Canada - Atlantic, 9 Grove St., Dartmouth, N.S., Canada \\ ${ }^{\mathrm{b}}$ Amtech Aeronautical Ltd, Medicine Hat, AB, Canda \\ ${ }^{\mathrm{c}}$ Defence Research and Development Canada - Suffield, Suffield, AB, Canada
}

Received 27 May 2009

Revised 11 August 2009

\begin{abstract}
Recent experiments involving near-contact underwater explosions on air-backed plates suggest the following failure mode categories: (1) holing and petaling, (2) complete or partial edge tearing due to shock only, (3) complete or partial edge tearing due to shock and bubble collapse, and (4) large deformation without rupture. Finite-element analysis was used to further investigate the detailed response and failure of the plates, and determine the limit between center plate holing and edge failure. When compared with experimental results, finite-elements showed good agreement with the failure modes of the plates and reasonable agreement with the experimental deformations. It was found that the linear interaction criteria (LIC) failure between plastic strain and through-thickness shear stress produced results closer to experiments than the quadratic interaction criteria (QIC). For the 18 gauge specimens it was found that the through-thickness shear dominated the failure initiation for very close proximity charges, with the direct strain becoming dominant as the standoff was increased. For the thinner 20 and 22 gauge plates the direct strain was always found to be the dominant factor in the failure criteria.
\end{abstract}

Keywords: Underwater explosions, shock, petaling, fluid-structure interaction, finite element analysis, marine structures, material failure

\section{Introduction}

Recent experiments by DRDC involving near-contact underwater explosions on air-backed plates suggest the following failure mode categories: (1) holing and petaling, (2) complete or partial edge tearing due to shock only, (3) complete or partial edge tearing due to shock and bubble collapse, and (4) large deformation without rupture.

Failure modes for blast loaded plates have been divided into three main modes as follows: Mode I: large inelastic deformation; Mode II: large inelastic deformation with tensile tearing; and Mode III: transverse shear failure. These modes have been further detailed depending on the degree of damage such as partial edge tearing being mode II* as an example. This paper looks at only the contribution of in-plane tensile strain and through thickness shear effects to failure and crack growth so the main modes are considered. Previous works on predicting the failure of plates subjected to blast loads have focused on the failure modes at the supports of the plates or near stiffeners in stiffened plates, with limited studies on center plate holing.

Rudrapatna et al. [12] studied numerically the edge failure of square plate specimens subjected to blast loading with a failure criteria based on combining bending, tension, and transverse shear effects with a linear (LIC) and quadratic (QIC) interaction criteria. The numerical investigation was carried out using a special purpose finite element analysis software called NAPSSE (Nonlinear Analysis of Plate Structures using Super Elements). In order

*Corresponding author. Tel.: +1 9024263100 Ext. 358; Fax: +1 902426 9654; E-mail: mark.riley@ drdc-rddc.gc.ca. 
to account for transverse shear at the boundary, fictitious stiff springs were placed at the boundaries and the resulting reaction forces were used to determine the shear stress. The results showed that the influence of transverse stress to the initial failure of the plate specimens was significant, and increased as the impulse was increased. They also found that the quadratic interaction criteria consistently predicted better results than the linear interaction criteria. Nurick et al. [8] implemented the finite element package ABAQUS to model large inelastic deformation of clamped circular plates subjected to blast loading. This study looked at different degrees of necking at the boundaries including no necking, necking at parts of the boundary, and necking around the entire boundary. The plates used as clamping plates were modified such that sharp edges as well as rounded corners were used. It was found that the clamping plate corners influenced the level of impulse at which the test specimen exhibits necking and subsequent failure at the boundaries. They found that the ABAQUS predictions for inelastic deformation without necking compared well with experiments. However, the variation between the predicted and experimental displacements increased as the impulse and subsequent displacements increased. Nurick et al. [9] studied fully built-in stiffened square plates subjected to blast pressure loading. The numerical study was carried out with finite element analysis using NAPSSE. The numerical analysis accounts for strain rate effects as well as nonlinear geometric and material effects with a failure criterion based on maximum strain. They found that the maximum displacement and deformed shape for the stiffened panels were well predicted. Also for small stiffeners the mode II failure location, tensile tearing at the support, was well predicted. However, with larger stiffeners the failure occurred at the supports in the numerical study, but in the experiments the plates failed at the stiffener. It was thought that these failures may be shear related, which was not considered in their study. Chung Kim Yuen and Nurick [2] and Langdon et al. [4] performed experimental and numerical studies on the response of quadrilateral stiffened plates due to uniform and localized blast loading. In both studies experiments were conducted on plates with different stiffener configurations and size variations. The numerical simulations were conducted with ABAQUS/Explicit 5.8. Temperature and strain rate effects were included in the modelling. Tearing in the models was predicted with high-temperature bands, as there was no material failure model available. With uniformly loaded plates stiffening did not reduce the tearing in the target plate, and may actually be detrimental to the strength by initiating tearing earlier. For localized loading of the targets, the stiffener configurations had a significant influence on the resulting deformations, by limiting the area affected by the loading. In both studies it was found that the large inelastic deformation was well predicted.

Studies investigating holing in target plates include those by Ramajeyathilagam and Vendhan [11] who looked at predicting different failure patterns. In this study different failure modes were observed including large deformation, edge failure, as well as some center failure with the presence of edge failure. In previous studies the LIC failure criteria was only implemented for edge failure, where this study used it to predict central rupture. The predictions of central rupture were found to conform well to the experimental results; however no direct comparisons were shown in the paper for the cases of central rupture. Church et al. [1] conducted experiments and numerical simulations on large steel plates subjected to underwater contact charges. The simulations were performed using the Eulerian hydrocode GRIM to predict the plate loading and DYNA to model the response of the target plate. The fracture model used for the plate in the numerical simulations was the Goldthorpe Path Dependent Ductile Fracture model. Two different loading techniques were used from GRIM which included the impulsive loading only, i.e. the gaseous loading, and the impulsive plus water loading. In both cases one way loading was used, such that the hydrocode and Lagrangian solvers were not coupled. It was found that the failure could be adequately reproduced with the use of advanced constitutive models and a simple momentum deposition loading method. Wierzbicki [14] derived a closed form solution for predicting the number of petals for plate holing, the total energy absorbed by the system, as well as the final deformed shape for blast loading and projectile impact. For the blast loading a solution was developed for the radius of the center holing. The holing radius is a function of the charge radius, plate thickness, plate density, rupture strain, flow stress, the initial plate velocity, the critical plate velocity which is the minimum plate velocity that results in center holing, and a moment amplification factor. The ratio of the initial plate velocity to the critical value can be substituted with the impulse or charge mass ratio if these critical values are known. In order to apply this method either experimental or numerical simulation results must be used to determine the critical values. Using previously published experimental results, Wierzbicki was able to get good correlation between his theoretical solution and experimental results.

The primary objective of the current study is to investigate the holing and petaling and determine the dominant failure mechanism for center plate holing. Experiments were conducted on rigidly-clamped circular and square 


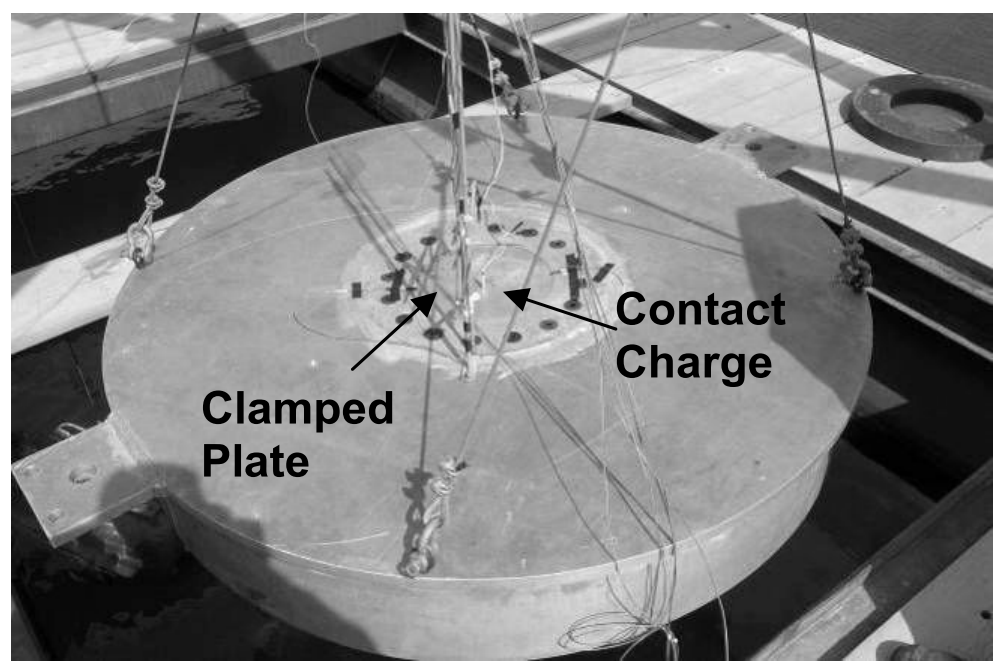

Fig. 1. Apparatus for conducting holing experiments on circular thin plates [13].

air-backed steel plates, in which underwater explosive charges were placed at varying standoffs including contact. The target plates were 0.76 to $1.3 \mathrm{~mm}$ thick with either a square loaded area of $254 \mathrm{X} 254 \mathrm{~mm}$, or a circular plate with a diameter of $254 \mathrm{~mm}$. The circular plates were made from ASTM A653 steel and the square of either ASTM A1008 mild steel or 350WT notch-toughened steel. High-explosive charges of $1.1 \mathrm{~g}$ and $20 \mathrm{~g}$ were detonated in near-contact with the plate, such that the loading seen by the plate was dominated by the shock pressure and the motion-induced cavitation. At near-contact (less than 0.1 times the bubble radius) holing, edge failure due to shock, and large plastic displacements without rupture, were all observed in the plate specimens. Measurements included free field pressure, high-speed video and post-test deformations of the specimens.

With limited experimental results, finite-element analysis was used to further investigate the detailed response and failure of the plates, and to determine the dominant failure mechanism as well as the standoff limit between holing and edge failure or no failure. The FE analyses were carried out with LS-DYNA using two different failure criteria based on a combination of normalized transverse shear stress and direct strain. The simulations were carried out for varying standoffs until the progression from holing to edge failure or no failure was observed. Finite-element analyses showed good agreement with the failure mode and reasonable agreement with post-test deformations.

\section{Experimental investigation}

The experiments relevant to the test cases simulated in this paper were conducted at the DRDC Suffield UNDEX pond facility. The tests consisted of plate-holing experiments with explosive charges in near-contact and in contact with the target steel plates. One series of tests was conducted on thin round plates made of A653 steel, as reported by Slater et al. [13]. In this work, $1.3 \mathrm{~mm}$ thick plates were clamped in a larger $1.5 \mathrm{~m}$ diameter apparatus with a RP-83 1.1 g RDX detonator mounted at the center, as shown in Fig. 1. The explosively-loaded area of the plate was $254 \mathrm{~mm}$ in diameter. The entire apparatus was flipped over and lowered into the water such that the target plate was submerged to a depth of approximately $0.5 \mathrm{~m}$.

A second series of tests were conducted with thin square plates made of mild (A1008) and 350WT steel, as reported by Lee et al. [5]. The plates ranged from 0.76 to $1.3 \mathrm{~mm}$ thick with an area of $254 \times 254 \mathrm{~mm}$ directly exposed to the explosion loading. The circular flanges of the target plates were rigidly clamped in a drum-shaped apparatus $610 \mathrm{~mm}(2 \mathrm{ft})$ in diameter as shown in Fig. 2. The apparatus has an air-tight cavity so that when submerged, the loaded area of the target plate is air-backed. Although the explosive charge shown in Fig. 2 is located at a large standoff distance from the plate, the tests relevant to this paper were conducted with a $1.1 \mathrm{~g}$ RDX charge in contact or near-contact with the plate. The apparatus was submerged to a depth of approximately $6.5 \mathrm{~m}$ for testing. 


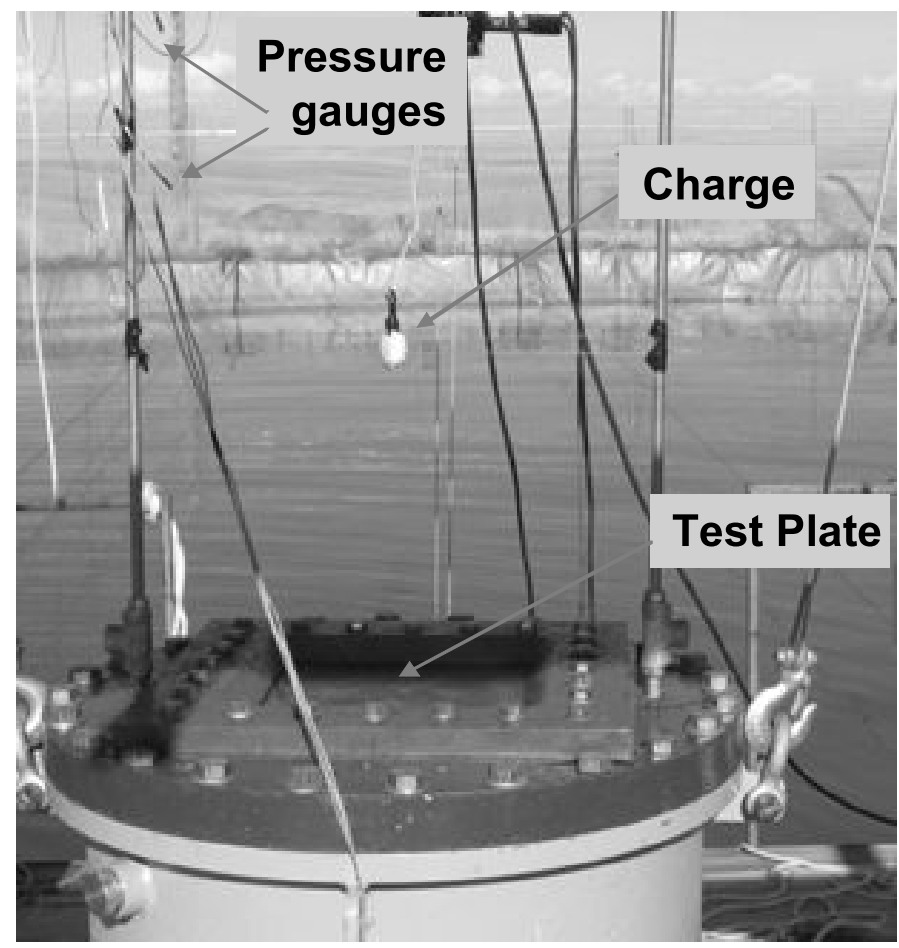

Fig. 2. Apparatus for explosively testing thin square plates [5].

\section{Numerical analysis}

The finite element analysis for this study was carried out with LS-DYNA [6,7]. The LS-DYNA explicit solver uses a central difference time integration scheme in conjunction with a subcycling approach, as outlined in their theory manual [7]. The time step size is determined by LS-DYNA based on the time for a transient wave to progress through an element. For problems involving explosions it is recommended, and therefore implemented in this study, to reduce the time step by a factor of 0.67. The plates were modeled using four-noded Hughes-Liu shell elements. For through thickness numerical integration the Lobatto method was used. The advantage of this technique over Gauss integration is that the outer most nodes are placed on the surfaces of the elements. The plate was modeled out to the location of the bolts used to clamp the plate in the fixture. At the location of the bolts, the nodes were fixed in all directions. The remaining nodes outside the loading area were restrained from displacing in the y-direction, (i.e. out-of-plane), which allowed for the in-plane movement which was observed in the experiments. The mesh used for the plate was very fine, consisting of approximately 60,000 elements. With the scope of this study being focused on the transition from center failure to edge failure, the mesh at the center and loaded edges of the plate was refined. The plate mesh used for the square plates is shown in Fig. 3(a). This mesh promotes a four petal formation due to the symmetry in the mesh. A triangular slice plate mesh was developed to promote a three petal failure, however the elements at the center of the plate were severely skewed and resulted in premature failure. Therefore, this mesh was not investigated any further. Altering the chosen mesh to allow for different petal formation patterns caused the elements to become extremely distorted, which was the main reason for choosing a simplistic mesh.

The water and air were modeled using an Eulerian mesh, as shown in Fig. 3(b) with the null materials in conjunction with an equation of state, EOS. The EOS's implemented for this study were the linear polynomial and Gruneisen for the air and water respectively. The mesh of the fluid was significantly refined in the y-direction between the charge and the plate. It was graded such that the minimum element size was $0.4 \mathrm{~mm}$ at the surface of the plate. The loading was achieved by modeling the shock wave generated from the detonation of the explosive. The explosive was defined using the "initial volume fraction geometry" keyword which allows the explosive to be modeled without the requirement of a very refined mesh for small charges. Due to the cylindrical shape of the $1.1 \mathrm{~g}$ RDX charge, the 
Table 1

Target plate material properties

\begin{tabular}{lcccccccc}
\hline & $\rho \mathrm{g}\left(\mathrm{Kg} / \mathrm{m}^{3}\right)$ & $\mathrm{E}(\mathrm{GPa})$ & $\mathrm{F}_{S}$ & $\mathrm{E}_{T}(\mathrm{Gpa})$ & $\mathrm{C}(1 / \mathrm{s})$ & $\mathrm{p}$ & $\mathrm{S}_{y}(\mathrm{Mpa})$ & $\mathrm{S}_{u}(\mathrm{Mpa})$ \\
\hline $\mathrm{A} 1008$ & 7850 & 164.3 & 0.37 & 1.562 & 40.4 & 5 & 189.5 & 312.6 \\
350WT & 7850 & 194.4 & 0.18 & 1.455 & 3200 & 5 & 265.1 & 335.8 \\
$\mathrm{~A} 653$ & 7870 & 210 & 0.18 & 2.10 & 100 & 10 & 255.0 & 360.0 \\
\hline
\end{tabular}

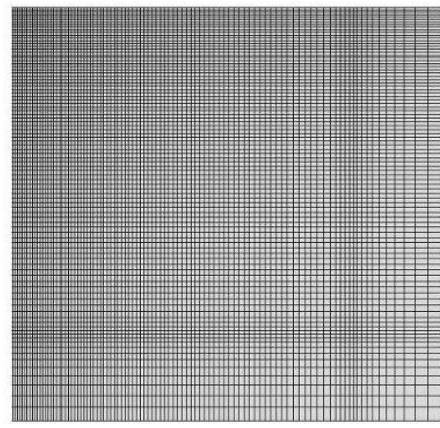

(a)

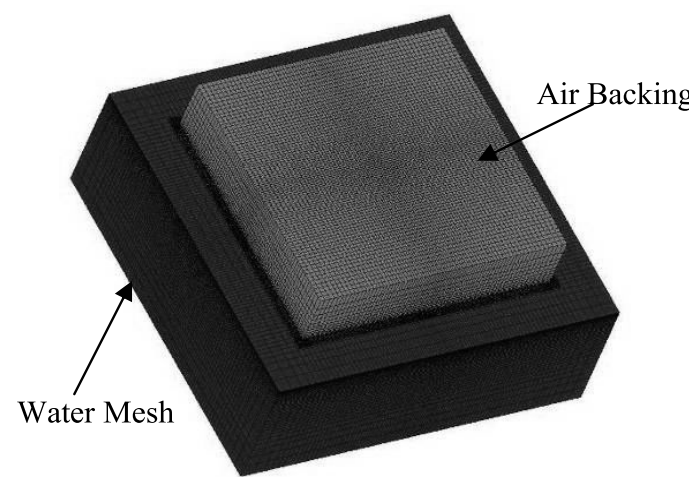

(b)

Fig. 3. Finite element meshes used for LS-DYNA analysis (a) Quarter of plate mesh (b) Fluid mesh.

standoff is taken to be the separation distance between the charge and the plate. However, for the $20 \mathrm{~g}$ C4 charge the standoff is the distance to the center of the sphere, which has a radius of $14.4 \mathrm{~mm}$.

The analysis was run to a termination time of between 1.5 and 2.5 milliseconds, which is determined to be when the petal tip velocity approaches zero. The loading is applied by coupling the fluids in contact with the plate to the plate surfaces using a penalty coupling approach. This is performed with the automatic coupling process within LS-DYNA, "constrained_lagrange_in_solid” [6,7]. When elements fail they are removed from the calculations, while active elements remain coupled to the fluids in the same manner as before. Before a crack opens, only the water on the loading side and the air on the back surface are coupled to the plate. But once a crack forms, coupling could be between any of the fluids/gases such as water, explosive products, or air. This is due to the fluids mixing within the Eulerian mesh near the cracks. At the termination time, the bubble/products of the explosive fill most of the area around the hole. Because of the short duration of the simulation, the fluid flow through the crack is very small at the termination. Longer duration simulations would be needed to see the effects fluid flow into the air cavity.

\section{Material models}

For the square plate specimens, tensile coupons were used to determine the material properties of the plating. This was not performed for the circular plates, so standard book values for A653 Grade 37, were used for the analyses. The material properties of the metals used in this study are shown in Table 1.

The explosive materials were modeled with the high explosive burn material model in conjunction with the JWL equation of state. The $1.1 \mathrm{~g}$ detonator consists of $1.03 \mathrm{~g}$ of RDX+binder and $0.08 \mathrm{~g}$ PETN for initiation. Given an average density of the RDX with a binder of $1.55-1.70 \mathrm{~g} / \mathrm{cc}$, it was assumed that the material was composition A, which is composed of $91 \%$ RDX and $9 \%$ wax and has a density of $1.65 \mathrm{~g} / \mathrm{cc}$. It was found with CHEETAH [3] that including the small amount of PETN, as compared to using $100 \%$ of composition A, had minimal effects on the JWL EOS parameters. This was reinforced with some LS-DYNA analyses performed with the inclusion of the PETN and using only composition A. Therefore for the purpose of this study the RP-83 detonator was modeled using $1.1 \mathrm{~g}$ of composition $\mathrm{A}$. The $\mathrm{C} 4$ explosive was modeled using a composition including $91 \%$ RDX with the other $9 \%$ made up of various additives. The material properties and EOS parameters for the explosive materials are shown in Table 2.

A user material model was implemented for the Hughes-Liu shell elements used for the target plates, based on the theory of the plastic kinematic material model, material 3, within LS-DYNA. The user material allows for isotropic 
Table 2

Material properties and EOS parameters used to model explosive materials

\begin{tabular}{lcccccccc}
\hline & $\rho \mathrm{g}\left(\mathrm{Kg} / \mathrm{m}^{3}\right)$ & $\mathrm{A}(\mathrm{Gpa})$ & $\mathrm{B}(\mathrm{Gpa})$ & $\mathrm{R} 1$ & \multicolumn{1}{c}{$\mathrm{R} 2$} & $\omega$ & $\mathrm{E}_{0}(\mathrm{KJ} / \mathrm{cc})$ & $\mathrm{CJ}(\mathrm{Gpa})$ \\
\hline $\mathrm{C} 4$ & 1600 & 488.3 & 6.502 & 4.392 & 1.006 & 0.3723 & 8.785 & 23.17 \\
$\mathrm{RP}-83$ & 1650 & 611.3 & 10.65 & 4.4 & 1.2 & 0.32 & 8.90 & 26.4 \\
\hline
\end{tabular}

Table 3

Cowper-Symonds strain rate parameters used for the various metals [10]

\begin{tabular}{lcc}
\hline Steel type & D & n \\
\hline Mild A1008 & 40.4 & 5 \\
350WT & 3200 & 5 \\
Galvanized A653 & 100 & 10 \\
\hline
\end{tabular}

or kinematic hardening, as well as any combination of the two. Strain rate effects were also included within the material definition using the Cowper-Symonds relation to compute the dynamic yield stress $\left(\sigma_{d y}\right)$, as shown by Eq. (1)

$$
\sigma_{d y}=\left(\sigma_{y}+\beta E_{p} \varepsilon_{e f f}^{p}\right)\left(1+\left|\frac{\dot{\varepsilon}}{D}\right|^{1 / n}\right)
$$

where $\sigma_{y}$ is the static yield stress, $\beta$ is the material hardening factor, $\mathrm{E}_{p}$ is the plastic modulus, $\varepsilon_{e f f}^{p}$ is the effective plastic strain, and $\mathrm{D}$ and $\mathrm{n}$ are the strain rate parameters that vary with material. The values used for the strain rate parameters in these studies are shown in Table 3.

The main goal of developing the user material was to implement a failure criteria that combined in-plane tensile tearing, Mode II, and through-thickness shear tearing, Mode III, for plate holing failures. This was achieved through the linear interaction criteria (LIC) and quadratic interaction criteria (QIC), as proposed by Rudrapatna et al. [12], and shown in Eqs (2) and (3).

$$
\begin{aligned}
& L I C=\left|\frac{\varepsilon_{e}}{\varepsilon_{\text {rup }}}\right|+\left|\frac{\tau_{e}}{\tau_{\text {dult }}}\right| \\
& \text { QIC }=\left|\frac{\varepsilon_{e}}{\varepsilon_{\text {rup }}}\right|^{2}+\left|\frac{\tau_{e}}{\tau_{\text {dult }}}\right|^{2}
\end{aligned}
$$

Here $\varepsilon_{e}$ is the true element membrane strain, $\varepsilon_{r u p}$ is the true rupture strain, $\tau_{e}$ is the maximum of the through thickness shear stresses in the element, and $\tau_{\text {dult }}$ is the dynamic ultimate shear strength determined with equation 4 , in which $\sigma_{u l t}$ is the static ultimate strength of the material.

$$
\tau_{d u l t}=\frac{\sigma_{u l t}}{\sqrt{3}}\left(1+\left|\frac{\dot{\varepsilon}}{D}\right|^{1 / n}\right)
$$

Elements were deemed to have failed when the failure criteria exceeded a value of 1.0, at which point the elements were removed from the calculations.

\section{Experimental results}

Although the overall scope of the experimental program conducted at DRDC Suffield involves several types of damage, the results for this study focus on those experiments resulting in holing of the plate. These experiments are limited to the $1.1 \mathrm{~g}$ RDX charge in contact with all plate specimens, as well as small standoffs from the circular plate. Due to the sometimes catastrophic failures with close proximity charges, instrumentation in the experiments was limited, and the only results available for comparison purposes include the number of petals, maximum permanent 


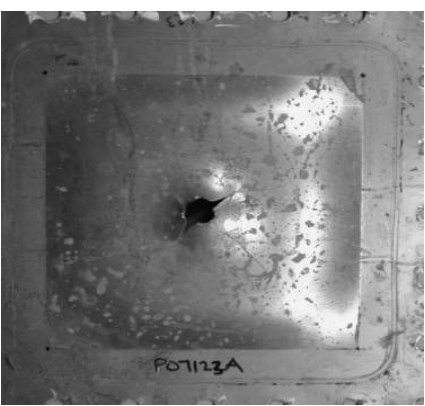

Test 1

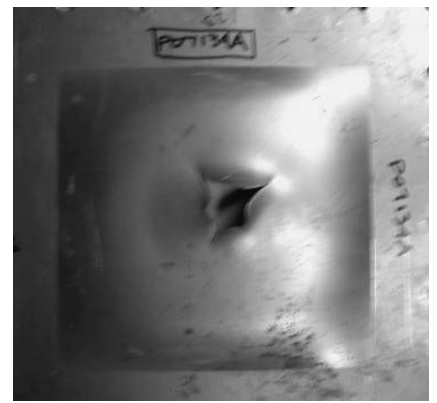

Test 2

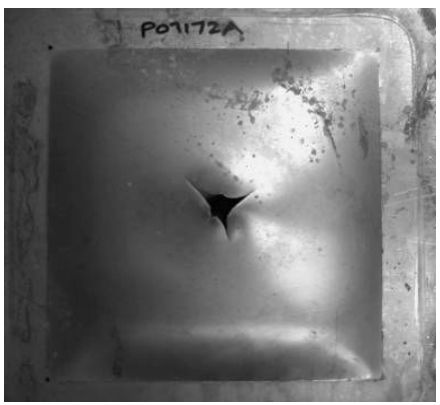

Test 3

Fig. 4. Failure Patterns for the Three Tests on the 18ga Mild Steel Specimen with a $1.1 \mathrm{~g}$ RDX Charge in Contact.

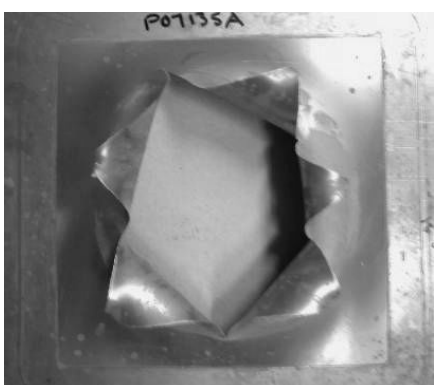

(a)

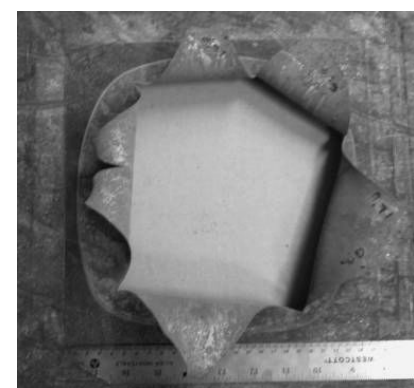

(b)

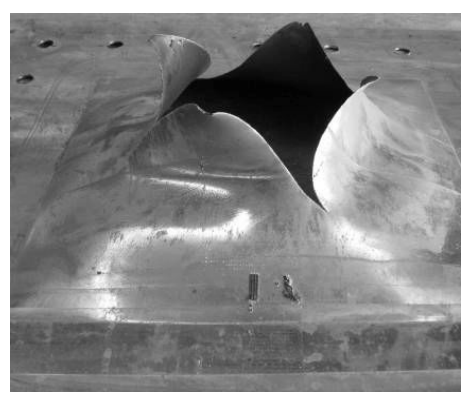

(c)

Fig. 5. Failure Patterns for different specimens with a $1.1 \mathrm{~g}$ RDX charge in contact (a) 20 gauge mild steel, (b) 22 gauge mild steel, and (c) 350WT steel.

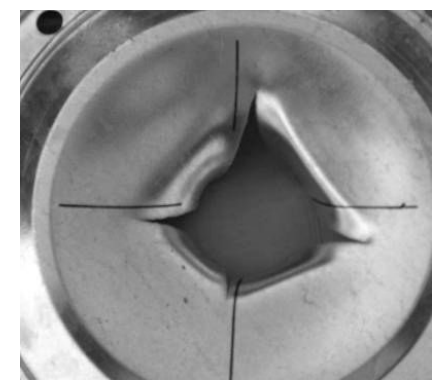

(a)

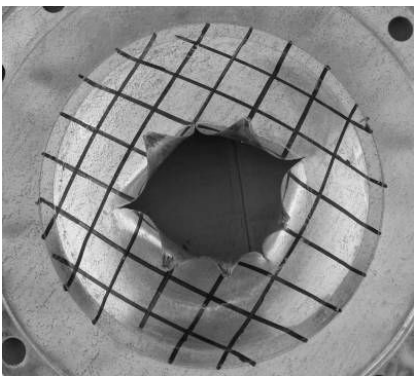

(b)

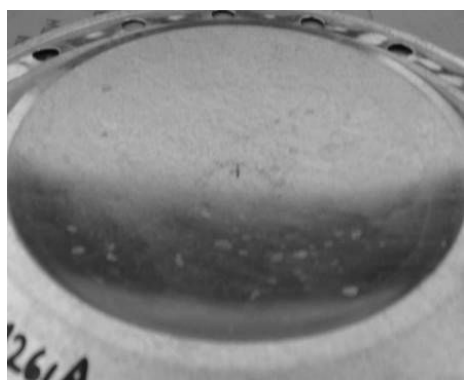

(c)

Fig. 6. Failure Patterns for different circular A653 steel specimens with a $1.1 \mathrm{~g} \mathrm{RDX}$ charge in (a) contact, (b) contact, and (c) $10 \mathrm{~mm}$ standoff [13].

deformation of the petals, the hole area, and in some cases the displacement at the base of the petals. Figures 4 through 6 show some of the failure patterns for the varying tests.

As Fig. 4 shows, there was a significant difference observed in the failure patterns for the 18 gauge mild steel plates subjected to the $1.1 \mathrm{~g}$ contact charge. Two of the failures produced three petals, while the other had four. The hole areas also ranged from $300 \mathrm{~mm}^{2}$ up to $870 \mathrm{~mm}^{2}$. Factors affecting these failure patterns include local imperfections in the plate, and small variations in the charge positioning. The variation in failure patterns under the same loading conditions was also observed in the A653 steel circular test specimens as seen in Figs 6(a) and 6(b). The resulting maximum petal displacements and holing area are shown in Table 4 for all tests. In the cases where more than one experiment was conducted, the average values are shown in the table. If the failure patterns were different between the experiments, the four petal results were used. 
Table 4

Experimental results for various close proximity $1.1 \mathrm{~g}$ RDX charge experiments

\begin{tabular}{lllllr}
\hline Plate specimen & $\begin{array}{l}\text { Plate thick- } \\
\text { ness }(\mathrm{mm})\end{array}$ & $\begin{array}{l}\text { Standoff } \\
(\mathrm{mm})\end{array}$ & $\begin{array}{l}\text { Avg. petal dis- } \\
\text { placement }(\mathrm{mm})\end{array}$ & $\begin{array}{l}\text { Avg. petal root dis- } \\
\text { placement }(\mathrm{mm})\end{array}$ & $\begin{array}{l}\text { Hole area } \\
\left(\mathrm{mm}^{2}\right)\end{array}$ \\
\hline 18ga A1008 contact & 1.21 & 0.0 & 45.3 & - & 870 \\
20ga A1008 contact & 0.91 & 0.0 & 73 & - & 13118 \\
22ga A1008 contact & 0.76 & 0.0 & 73 & - & 22381 \\
350WT Steel contact & 1.30 & 0.0 & 65 & 18 & 9039 \\
A653 Steel contact & 1.27 & 0.0 & 70 & 28 & 6075 \\
A653 Steel 10 mm standoff & 1.27 & 10.0 & 23 & - & 0 \\
\hline
\end{tabular}

Table 5

Experimental results for various close proximity $1.1 \mathrm{~g}$ RDX charge experiments

\begin{tabular}{|c|c|c|c|c|c|c|}
\hline \multirow{2}{*}{ Plate specimen } & \multicolumn{3}{|c|}{ QIC Failure Criteria } & \multicolumn{3}{|c|}{ LIC Failure Criteria } \\
\hline & $\begin{array}{l}\text { Avg. petal dis- } \\
\text { placement (mm) }\end{array}$ & $\begin{array}{l}\text { Avg. petal root dis- } \\
\text { placement }(\mathrm{mm})\end{array}$ & $\begin{array}{l}\text { Hole area } \\
\left(\mathrm{mm}^{2}\right)\end{array}$ & $\begin{array}{l}\text { Avg. petal dis- } \\
\text { placement (mm) }\end{array}$ & $\begin{array}{l}\text { Avg. petal root dis- } \\
\text { placement }(\mathrm{mm})\end{array}$ & $\begin{array}{l}\text { Hole area } \\
\left(\mathrm{mm}^{2}\right)\end{array}$ \\
\hline $18 \mathrm{ga} \mathrm{A} 1008$ contact & 44.5 & 23.2 & 1770 & 48.0 & 25.4 & 2000 \\
\hline 20ga A1008 contact & 54.2 & 24.0 & 10000 & 56.0 & 32.5 & 9700 \\
\hline 22ga A1008 contact & 57.5 & 23.2 & 15300 & 58.3 & 24.0 & 16000 \\
\hline 350WT Steel contact & 55.5 & 16.6 & 5500 & 56.0 & 18.5 & 5500 \\
\hline A653 Steel contact & 45.4 & 15.0 & 4225 & 50.6 & 13.4 & 4900 \\
\hline A653 Steel $10 \mathrm{~mm}$ standoff & 16.1 & - & 0 & 16.2 & - & 0 \\
\hline
\end{tabular}

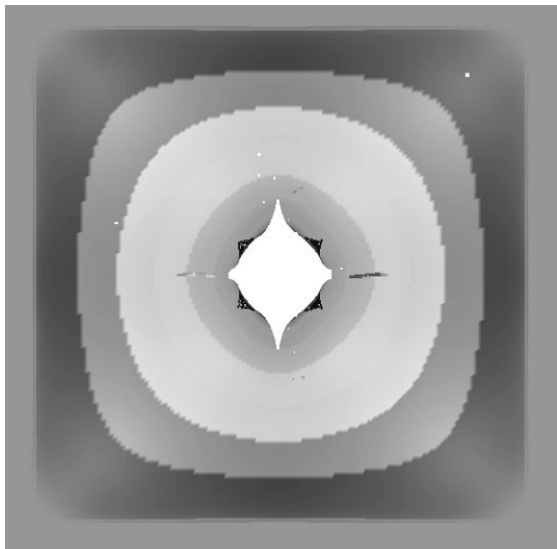

(a)

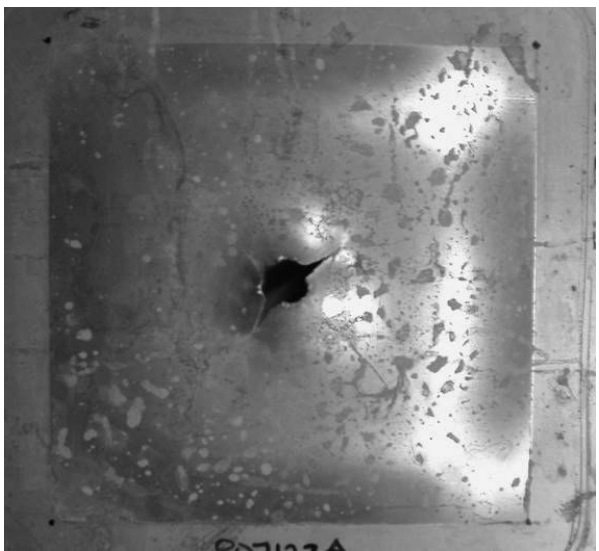

(b)

Fig. 7. Final petal formation of 18 gauge A1008 steel with $1.1 \mathrm{~g}$ RDX contact charge (a) Numerical (b) Experimental.

\section{Finite element results}

In order to validate the model, the maximum petal displacement and the hole areas were compared to the experimental results. Table 5 shows the results for the average petal tip and petal root displacements, and the hole area for all analyses.

Comparing Tables 4 and 5, the petal displacements are generally underestimated in the simulations, especially in the thinner plates. It was found that the difference in the predicted final deformations and damage areas were very small between the two failure criteria. One reason for this is that the numerical models were only simulated up to a maximum of 2.5 milliseconds, which is sufficient to account for the displacements due to the shock, but not for any effects of the bubble collapse. The computational effort needed to model bubble collapse was too large to justify extending the duration of the simulations. Another reason could be the presence of defects in the experimental specimens, which might lead to larger deformations. Figures 7 through 9 show the comparison between the final displaced shapes of the experimental and numerical results. These figures show that although the crack lengths in the simulations and experiments agree reasonably well, the petals do not fold back in the simulations as much as they 


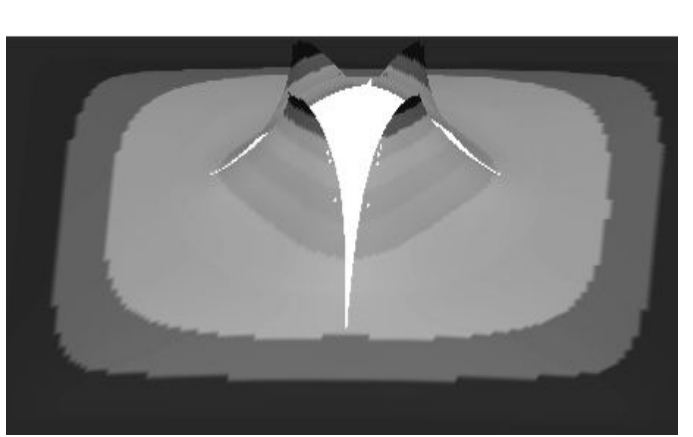

(a)

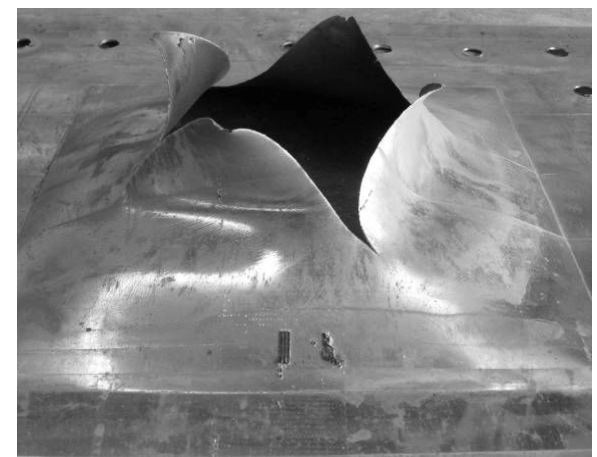

(b)

Fig. 8. Final petal formation of the $350 \mathrm{WT}$ steel with $1.1 \mathrm{~g}$ RDX contact charge (a) Numerical (b) Experimental.

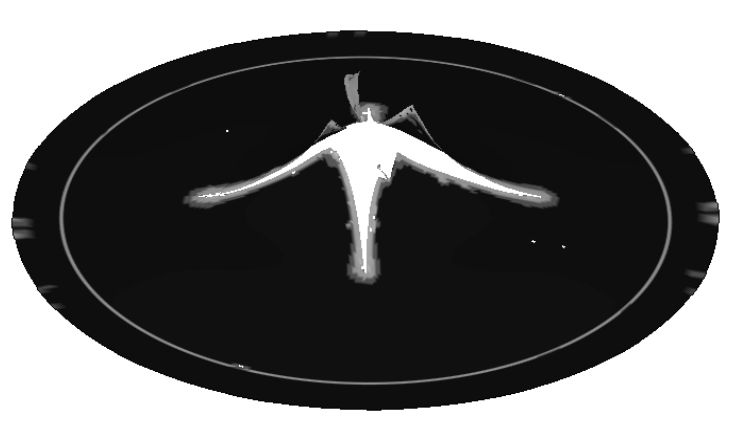

(a)

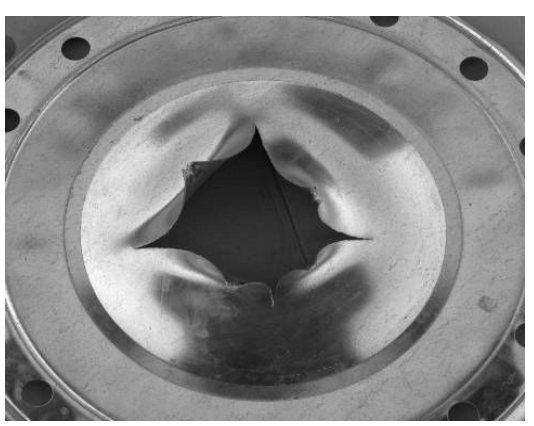

(b)

Fig. 9. Final petal formation of the A653 steel with 1.1 g RDX contact charge (a) Numerical (b) Experimental [13].

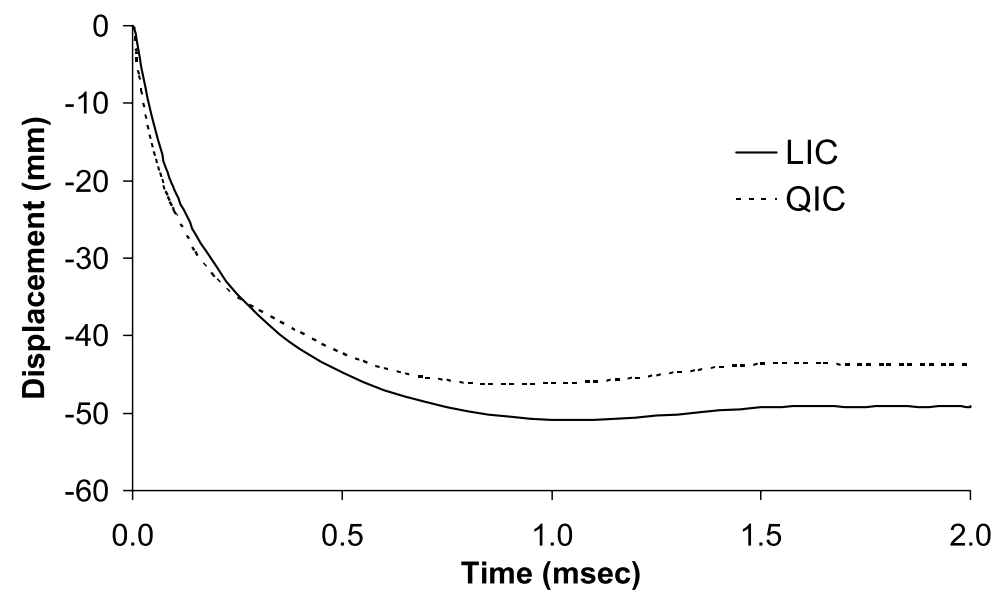

Fig. 10. Petal tip displacement for the 18 gauge mild steel plate subjected to a blast from a $1.1 \mathrm{~g}$ RDX detonator in contact.

do in the experiments. This points to inaccuracies in the strain rate and hardening parameters used. This could also help explain the under prediction of the hole area and petal displacements. The petal tip displacement time histories are shown in Figs 10 through 14 for the 18 gauge, 20 gauge, and 22 gauge mild steel plates, 350WT steel plate, and galvanized A653 Gr. 37 steel plate respectively.

The initiating failure mechanism for center holing using the QIC and LIC failure criteria were determined for the various plate specimens. This was performed by running analyses at various standoffs until the limiting center plate 


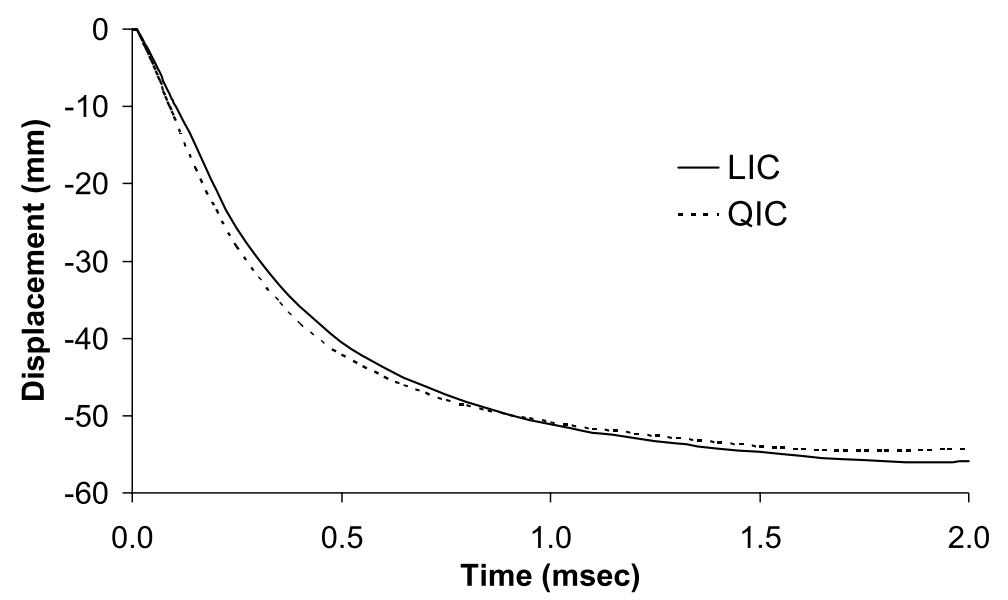

Fig. 11. Petal tip displacement for the 20 gauge mild steel plate subjected to a blast from a $1.1 \mathrm{~g}$ RDX detonator in contact.

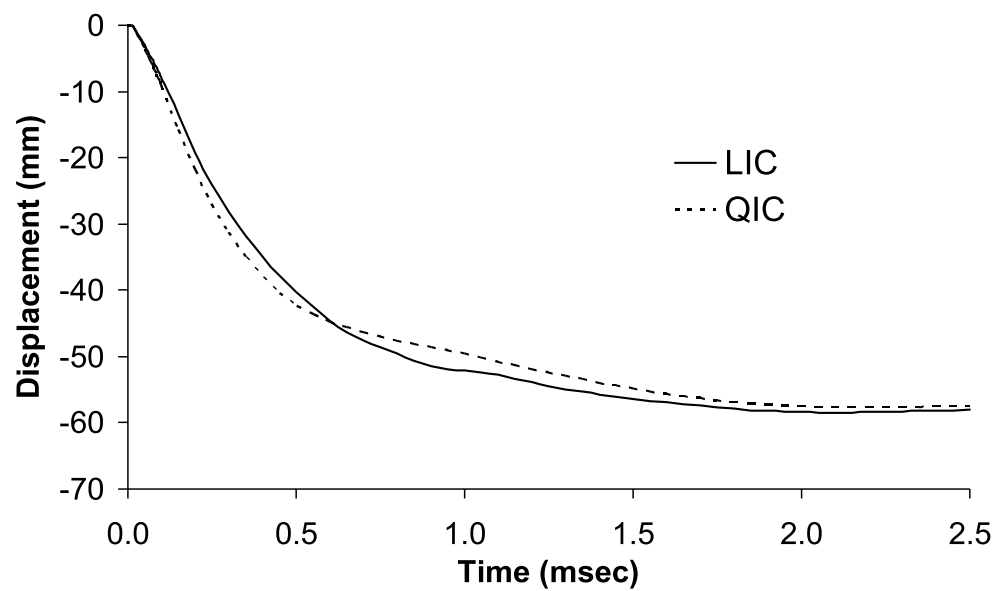

Fig. 12. Petal tip displacement for the 22 gauge mild steel plate subjected to a blast from a $1.1 \mathrm{~g}$ RDX detonator in contact.

failure standoff was reached. Figures 15, 17, 19, 21, and 23 shows the contribution of the in-plane strain Mode II factor to the failure criteria for initial failure for the various steel plates with the $1.1 \mathrm{~g}$ RDX and $20 \mathrm{~g} \mathrm{C} 4$ charges. Where 100 percent on the vertical axis would indicate that strain is the only contributor to failure, and less than 100 percent (ex. 60 percent) indicates the remaining contribution (ex. 40 percent) to failure is due to the shear stress term. For the $20 \mathrm{~g}$ charge, the standoff of $15 \mathrm{~mm}$ corresponds to contact with the target plate. Figures $16,18,20$, 22 , and 24 show the pressure and impulse time histories for the maximum standoff at which center plate failure occurs in each of the plates. The time axis has been significantly reduced to better show the pressure distribution. Due to the analyses not including later time effects such as the gas bubble, the pressure time histories remain fairly constant after 0.03 milliseconds, and the impulse shows a slight increase. As these plots show the pressure of the $1.1 \mathrm{~g}$ detonator charge is significantly higher than that of the $20 \mathrm{~g}$ charge; however the impulse of the $20 \mathrm{~g}$ charge is larger. One reasons for the lower limiting impulse of the RDX detonator is that fragments of the casing actually impacts the plate, which would lead to more loading than just the actual shock wave.

Figures 15, 21, and 23 shows that there is a significant difference in the initiating failure mechanism between the linear and quadratic failure criteria for the 18 gauge specimens. For the linear interaction criteria the combination of high shear stress and low in-plane strain is significant enough to result in shear dominated failure in the 18 gauge specimens for standoffs up to $16 \mathrm{~mm}, 28 \mathrm{~mm}$, and $22 \mathrm{~mm}$ for the mild, 350WT and galvanized steels, respectively. However, the shear stress magnitude is not large enough to cause shear dominated failure with the use of the QIC 


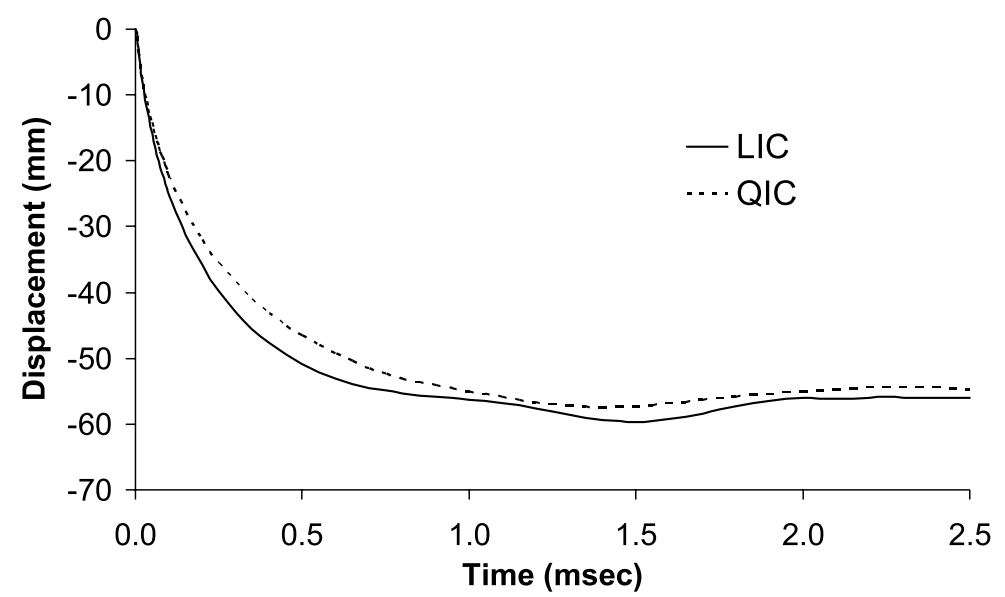

Fig. 13. Petal tip displacement for the 350WT steel plate subjected to a blast from a $1.1 \mathrm{~g}$ RDX detonator in contact.

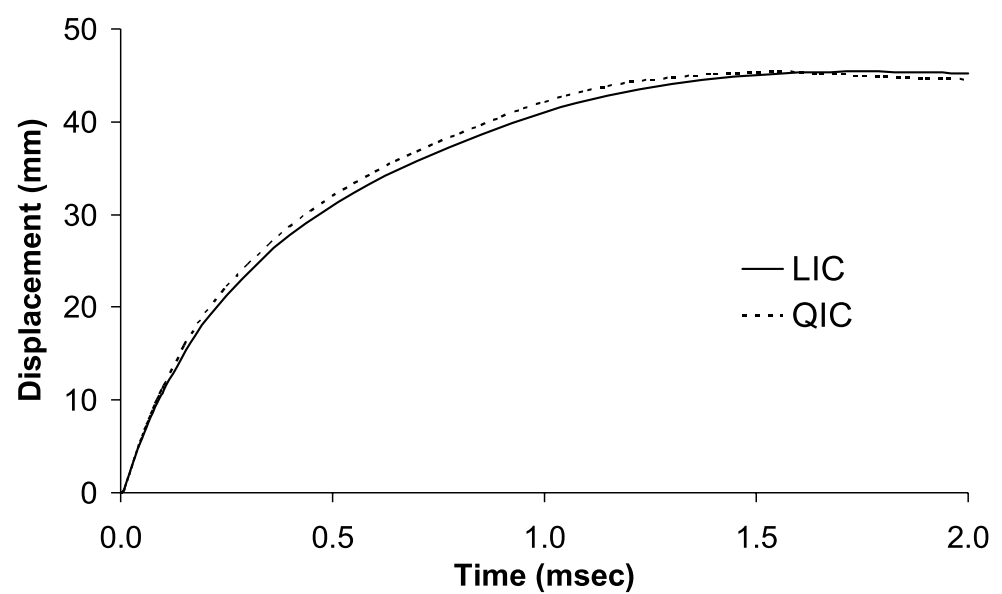

Fig. 14. Petal tip displacement for the galvanized A653 Gr. 37 steel plate subjected to a blast from a $1.1 \mathrm{~g}$ RDX detonator in contact.

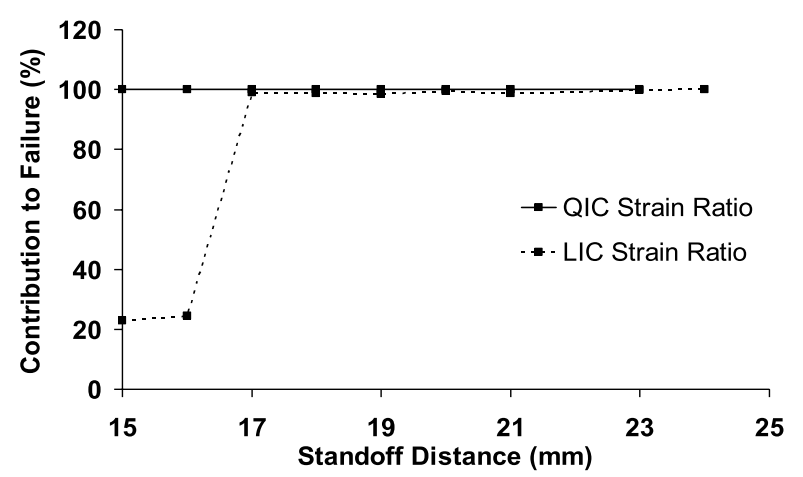

(a)

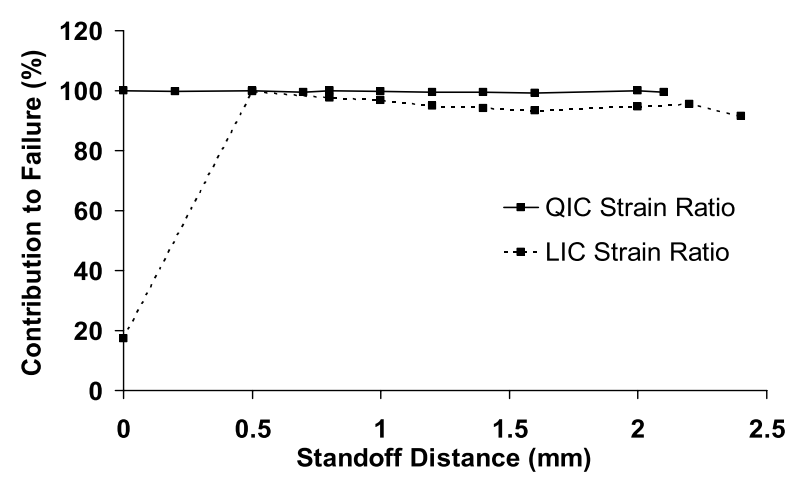

(b)

Fig. 15. Strain contribution to the LIC and QIC failure criteria for failure initiation in the 18 gauge mild steel plates with (a) $20 \mathrm{~g}$ C4 charge (b) $1.1 \mathrm{~g}$ RDX Charge. 


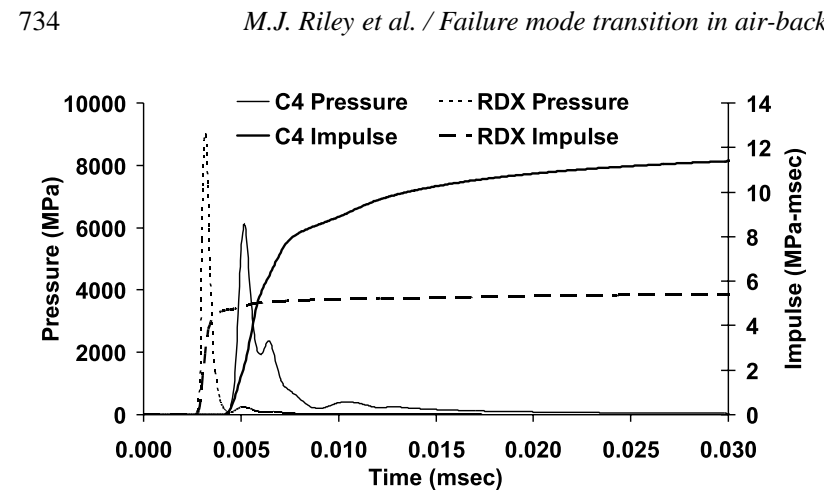

(a)

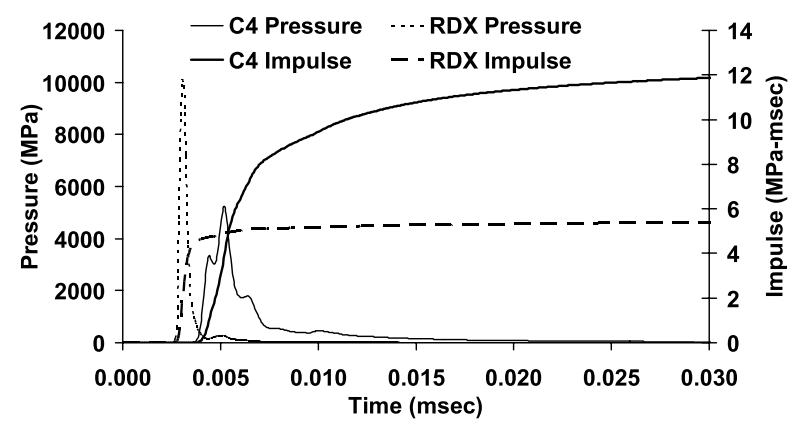

(b)

Fig. 16. Pressure and impulse at the limiting standoff of center plate failure for the 18 gauge mild steel plate (a) LIC failure criteria (b) QIC failure criteria.

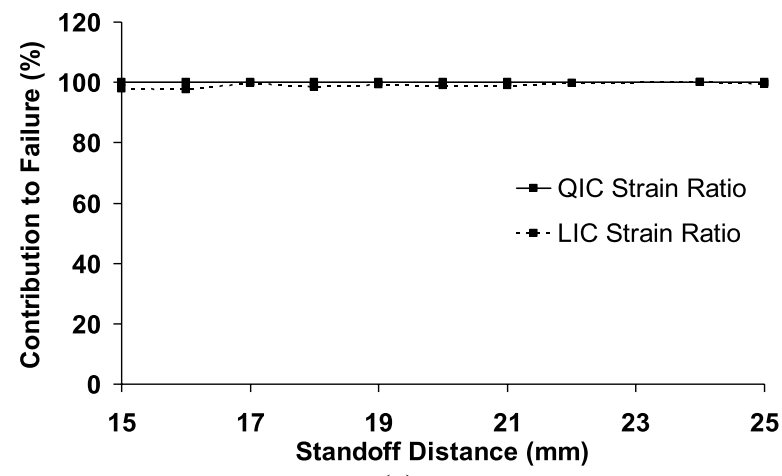

(a)

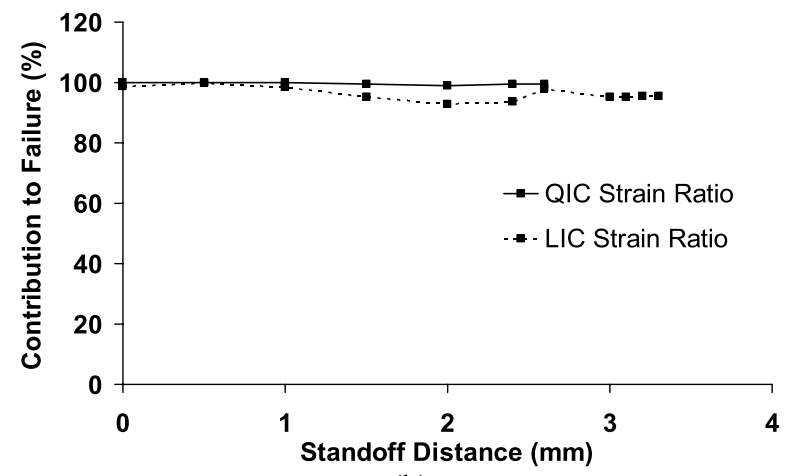

(b)

Fig. 17. Strain contribution to the LIC and QIC failure criteria for failure initiation in the 20 gauge mild steel plates with (a) $20 \mathrm{~g}$ C4 charge (b) $1.1 \mathrm{~g}$ RDX Charge.

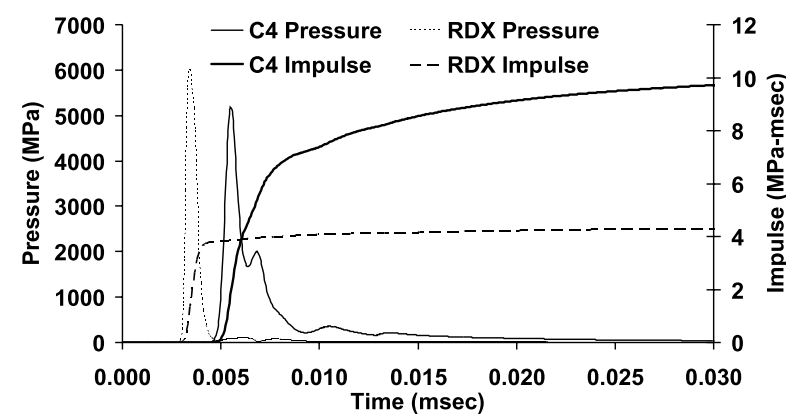

(a)

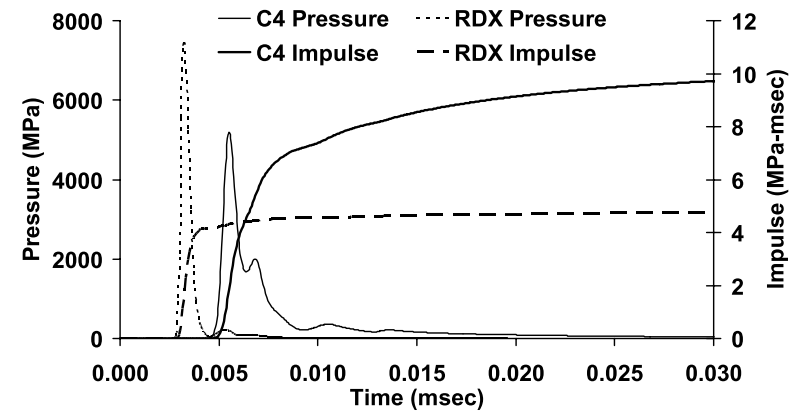

(b)

Fig. 18. Pressure and impulse at the limiting standoff of center plate failure for the 20 gauge mild steel plate (a) LIC failure criteria (b) QIC failure criteria.

failure criterion. Also, the shear stress does not reach a significant enough magnitude in the thinner, 20 and 22 gauge plates, to achieve a shear dominated failure with the use of either failure criteria. Fractographic analyses were performed on the fracture surface of some 18 gauge mild steel specimens. It was found that the primary failure mechanism was ductile shear failure for the $18 \mathrm{ga}$ mild steel specimen with the $1.1 \mathrm{~g}$ RDX charge in contact. This would indicate that the LIC failure criterion predicts the onset of failure in a more realistic manner than the QIC.

Along with the initiating failure mechanism, the dominant mechanism in the progression of failure over the 


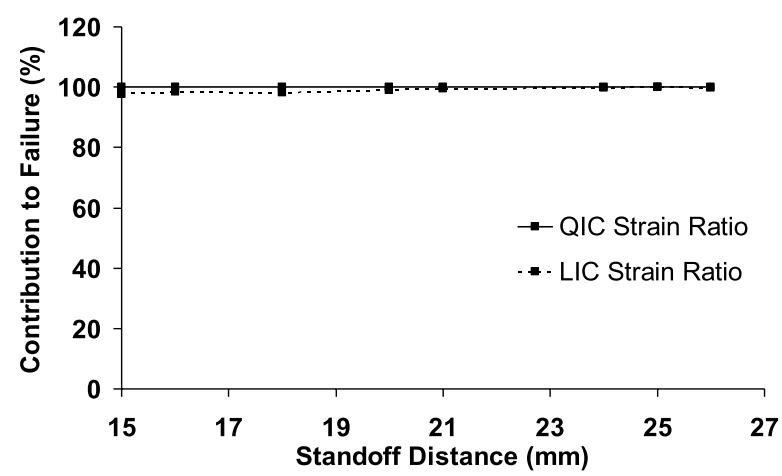

(a)

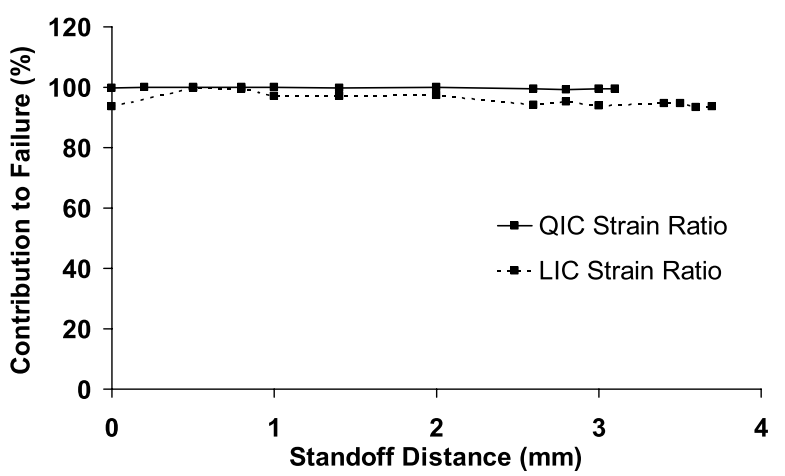

(b)

Fig. 19. Strain contribution to the LIC and QIC failure criteria for failure initiation in the 22 gauge mild steel plates with (a) $20 \mathrm{~g}$ C4 charge (b) $1.1 \mathrm{~g}$ RDX Charge.

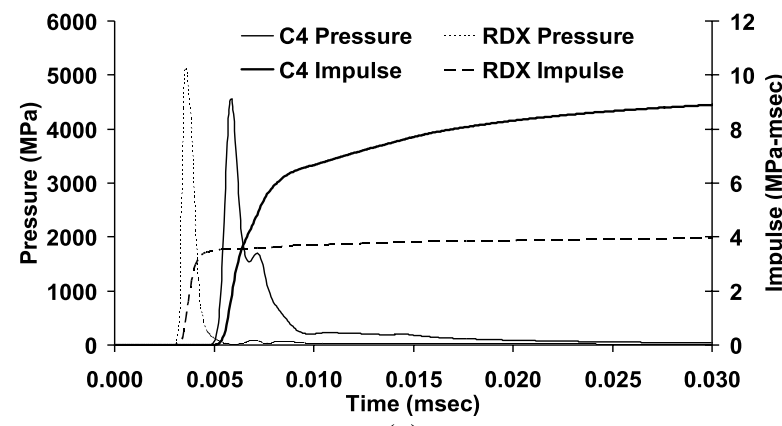

(a)

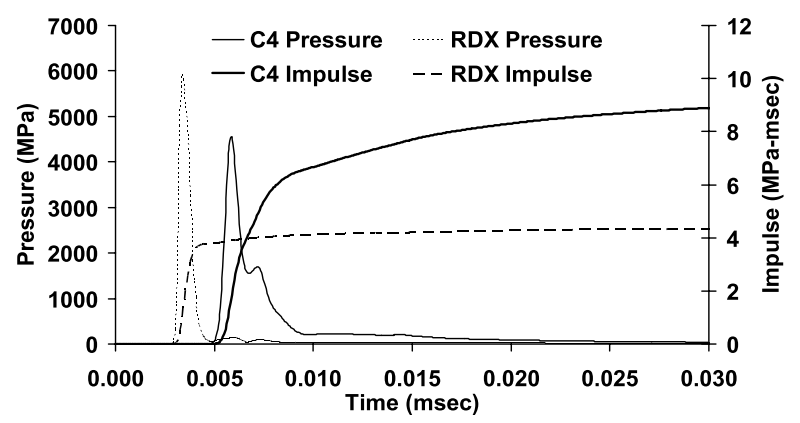

(b)

Fig. 20. Pressure and impulse at the limiting standoff of center plate failure for the 22 gauge mild steel plate (a) LIC failure criteria (b) QIC failure criteria.

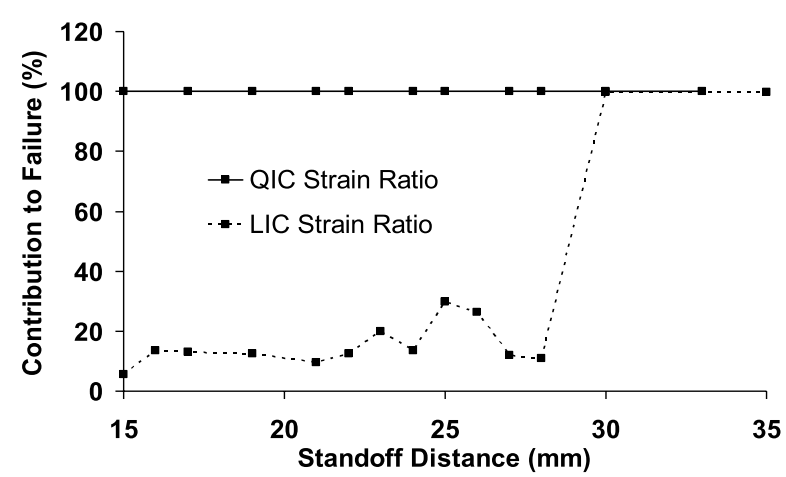

(a)

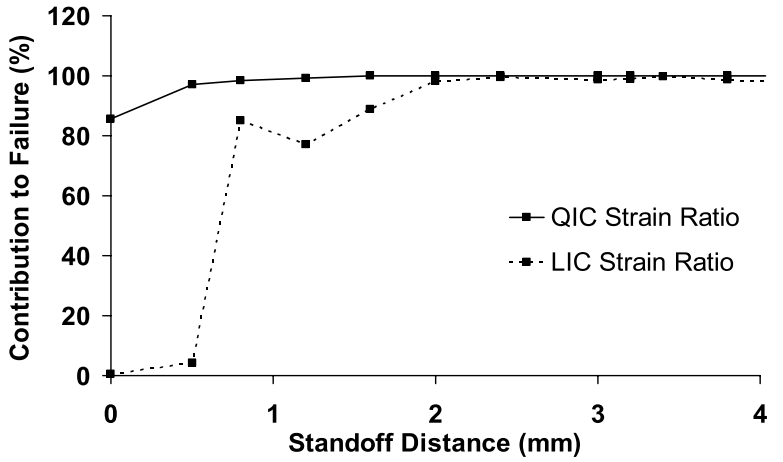

(b)

Fig. 21. Strain contribution to the LIC and QIC failure criteria for failure initiation in the $350 \mathrm{WT}$ steel plates with (a) $20 \mathrm{~g}$ C4 charge (b) $1.1 \mathrm{~g}$ RDX Charge.

duration of the petal formation was examined. It was found that plates exhibiting strain dominant initial failure had progression that was always strain dominant. Examples of the failure progression are shown in Fig. 25, where the failure progression was divided into new failure and failure progression. New failures are when elements fail that are not connected to other failed elements, such as the development of new cracks. Figure 26 shows examples of new failures and failure growth for the 350WT plate with the $20 \mathrm{~g} \mathrm{C} 4$ charge at $16 \mathrm{~mm}$ standoff. This only occurs 


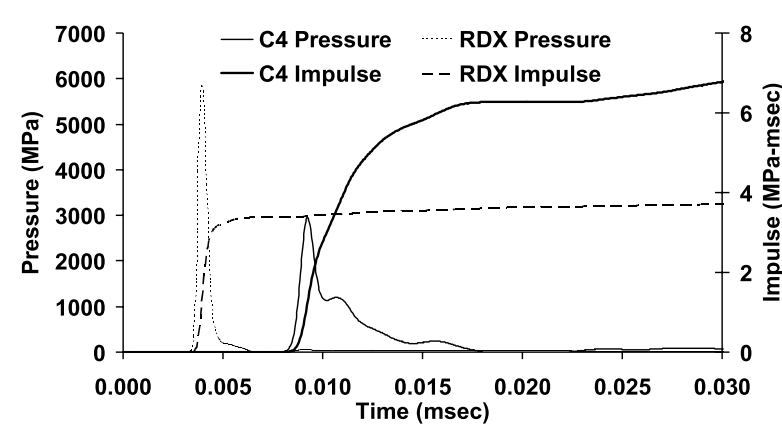

(a)

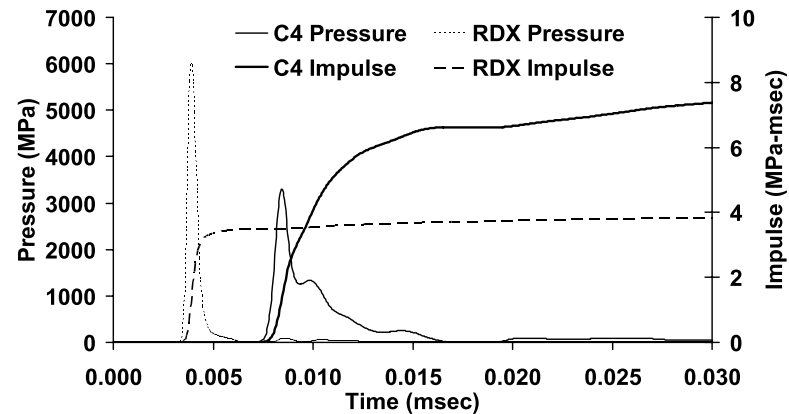

(b)

Fig. 22. Pressure and impulse at the limiting standoff of center plate failure for the $350 \mathrm{WT}$ steel plate (a) LIC failure criteria (b) QIC failure criteria.

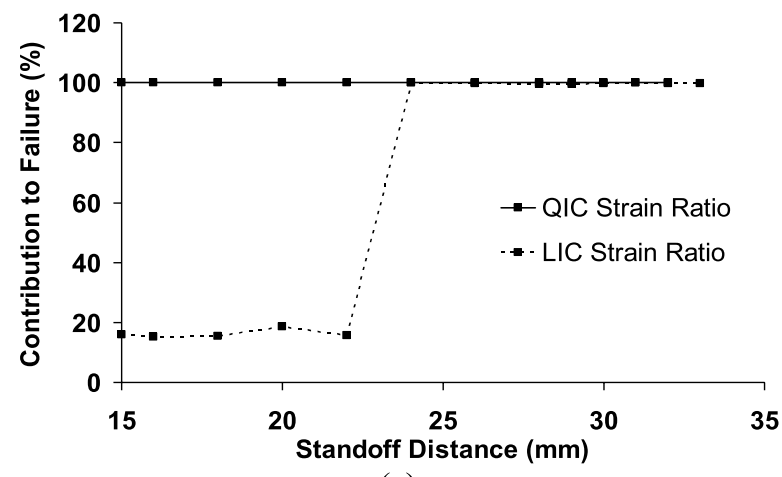

(a)

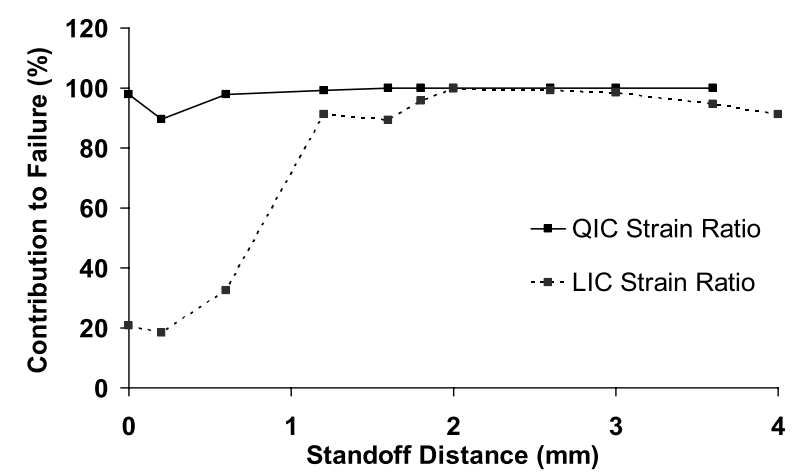

(b)

Fig. 23. Strain contribution to the LIC and QIC failure criteria for failure initiation in the Galvanized A653 Gr. 37 steel plates with (a) 20 g C4 charge (b) $1.1 \mathrm{~g}$ RDX Charge.

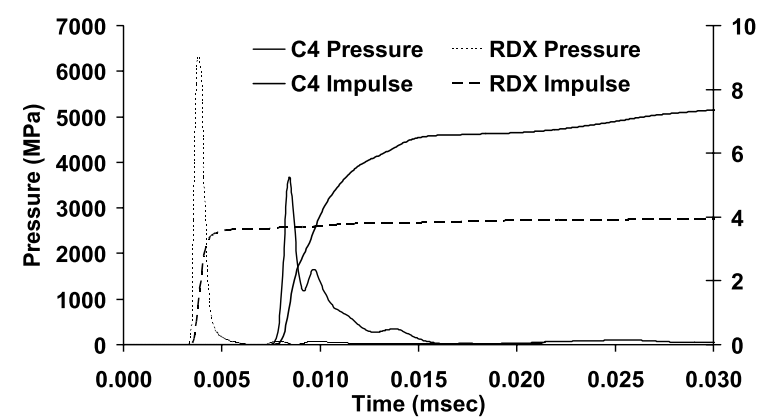

(a)

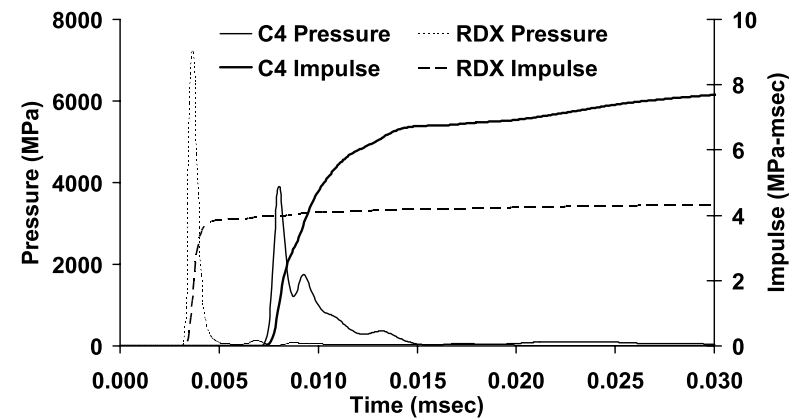

(b)

Fig. 24. Pressure and impulse at the limiting standoff of center plate failure for the galvanized A653 Gr. 37 steel plate (a) LIC failure criteria (b) QIC failure criteria. 
Table 6

Summary of standoff limits for plate holing

\begin{tabular}{lccccc}
\hline \multirow{2}{*}{ Target Specimen } & \multicolumn{3}{c}{ Standoff Limit for plate holing $(\mathrm{mm})$} \\
\cline { 2 - 3 } \cline { 5 - 6 } & \multicolumn{1}{c}{$1.1 \mathrm{~g}$ RDX } & & \multicolumn{2}{c}{$20 \mathrm{~g} \mathrm{C} 4$} \\
\cline { 2 - 3 } \cline { 5 - 6 } & LIC & QIC & & LIC & QIC \\
\hline 18 gauge A1008 & 2.4 & 2.1 & & 24 & 23 \\
20 gauge A1008 & 3.3 & 2.6 & & 25 & 25 \\
22 gauge A1008 & 3.7 & 3.1 & & 26 & 26 \\
350WT & 4.5 & 4.4 & & 35 & 33 \\
A653 & 4.0 & 3.6 & & 33 & 32 \\
\hline
\end{tabular}

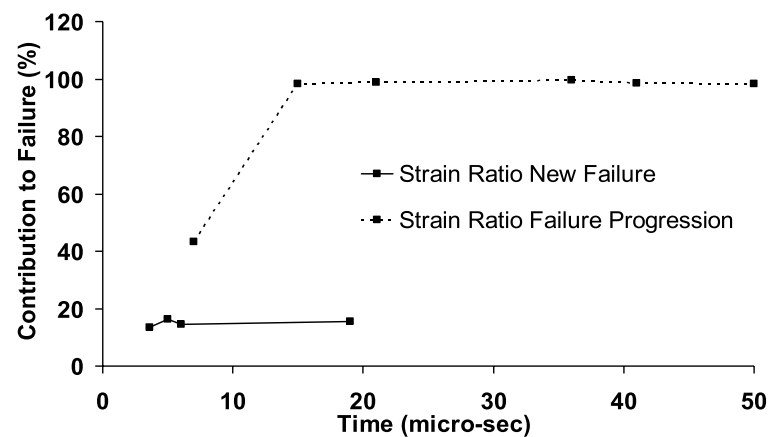

(a)

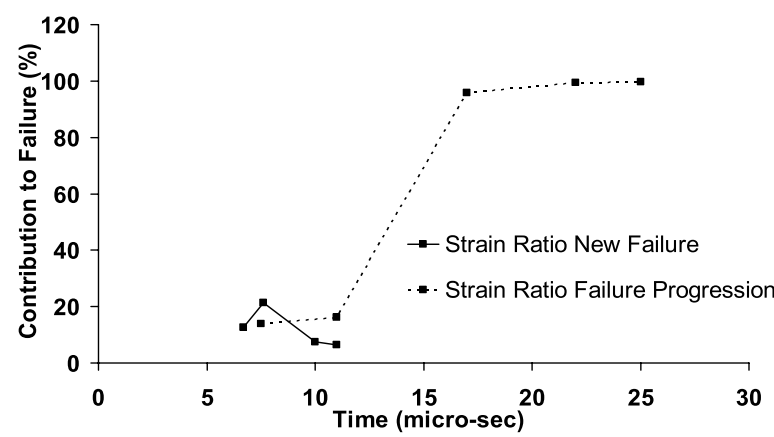

(b)

Fig. 25. Strain contribution to the LIC failure criteria for failure growth in the $350 \mathrm{WT}$ steel plate with (a) $20 \mathrm{~g} \mathrm{C} 4 \mathrm{charge}$ at $16 \mathrm{~mm}$ standoff (b) $20 \mathrm{~g} \mathrm{C} 4$ charge at $22 \mathrm{~mm}$ standoff.

in the very early stages of the analysis. Failure progression is the growth of the areas that have already failed, such as crack and petal growth.

\section{Summary and conclusion}

A study was performed to determine the standoff limit, as shown in Table 6 , to achieve center plate failure in various plates subjected to underwater shock from explosive charges. The failure criteria used included two methods combining the effects of in-plane strain and through thickness shear stress. These two factors were considered in a linear interaction criteria and a quadratic interaction criteria. The standoff limits with the QIC were always the same or smaller than those determined with the LIC.

In order to validate the modeling procedure and failure criteria, experimental results were used for comparison. It was found that the predicted damage due to the shock effects only, were essentially the same for the two failure models, as determined from the average petal displacements and the resulting hole area. The degree of damage for each of the failure methods was under-predicted by up to 35 percent for the QIC failure criteria and 30 percent for the LIC criteria when compared to experimental results. Possible reasons for this include defects in the experimental specimens that are not included in the analysis, small differences in charge location between the models and experiments, as well as unmodelled late-time effects due to bubble collapse. For the 18 gauge mild steel target plate, the petal displacement and hole area were over predicted. With the displacement and holing area being over-predicted in the 18ga A1008 plate specimen and under-predicted in the 20 and 22 gauge specimens, the choice of strain rate and hardening factors may affect the results more than expected. A parametric study will be performed in the future. The largest errors were observed in the A653 steel plate, which was modeled using standard book values for the material properties, unlike the other two where values were derived from coupon tests. Also the loading due to the shock wave of the two different charges show a very distinct difference in the pressure and impulse limit at failure. This is believed to be answered by the fragments of the detonator casing that impacts the plate specimens. A current study is being performed with a single charge material of different sizes to determine if a limiting value, of either impulse or pressure exists for the transition between center plate failure and edge plate failure. 


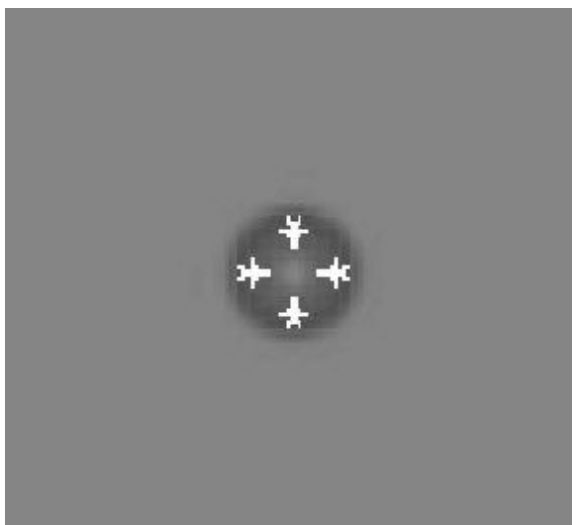

(a)

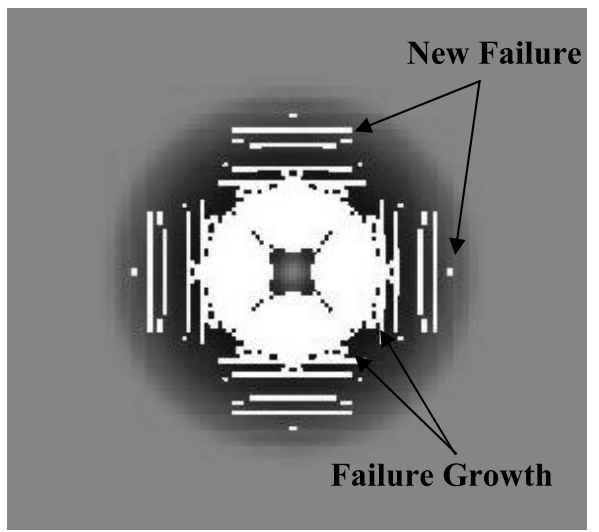

(c)

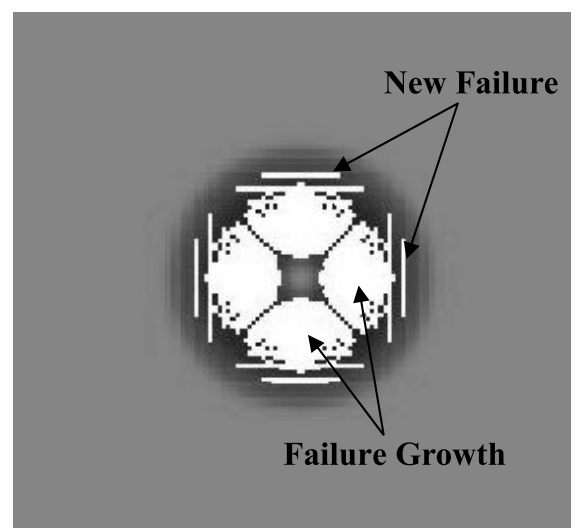

(b)

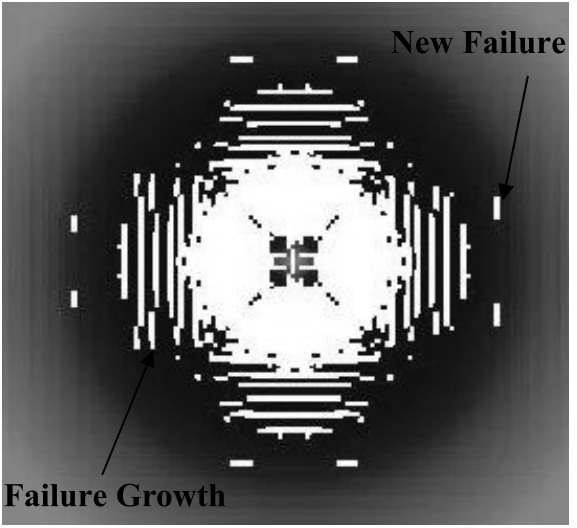

(d)

Fig. 26. Detailed view of hole initiation in the 350WT plate with the $20 \mathrm{~g} \mathrm{C} 4$ charge at a standoff of $16 \mathrm{~mm}$ (a) Failure Initiation at $3 \mu$ sec (b) $7 \mu \mathrm{sec}$ (c) $10 \mu \mathrm{sec}$ (d) $19 \mu \mathrm{sec}$.

When the initiation of center plate failure was examined there was a considerable difference between the two methods of assessing failure in the 18 gauge plate specimens. Using the linear interaction criteria it was found that hole formation was initiated by ductile shear failure at the center, and this is supported by fractographic inspection of the failure surfaces of the plate specimens. Implementing the quadratic interaction criteria produces similar final displacement results, however, failure initiation was always found to be governed by the in-plane strain capacity of the specimens. The formation of the petals was governed almost entirely by the in-plane strain capacity of the plate and although the initial failure is different, the overall crack growth in the specimens would progress in a similar fashion using either of the failure criteria. This is why the final deformations of the petals are very close between the two failure criteria.

\section{References}

[1] P. Church, M. Reynolds, W. Huntington-Thresher, R. Townsley and K. Sharpe, Underwater Plate Holing Studies, $21^{\text {st }}$ International Symposium on Ballistics, Adelaide, April 2004.

[2] S. Chung Kim Yuen and G.N. Nurick, Experimental and numerical studies on the response of quadrangular plates. Part I: subjected to uniform blast load, International Journal of Impact Engineering 31 (2005), 55-83.

[3] L. Fried, W. Howard, P. Souers and P. Vitello, Cheetah 3.0 User's Manual, Energetic Materials Center, Lawrence Livermore National Laboratory, 2001.

[4] G.S. Langdon, S. Chung Kim Yuen and G.N. Nurick, Experimental and numerical studies on the response of quadrangular plates. Part II: localized blast loading, International Journal of Impact Engineering 31 (2005), 85-111.

[5] J. Lee, M. Smith, J. Huang and G. Paulgaard, Deformation and rupture of thin steel plates due to cumulative loading from underwater shock and bubble collapse, Presented at the $79^{\text {th }}$ SAVIAC, Orlando, FL, 2008. 
[6] LS-DYNA Users Manual Version 971, Livermore Software Technology Corporation, 2008.

[7] LS-DYNA Theory Manual, Livermore Software Technology Corporation, 2007.

[8] G.N. Nurick, M.E. Gelman and N.S. Marshall, Tearing of blast loaded plates with clamped boundary conditions, International Journal of Impact Engineering 18 (1996), 803-827

[9] G.N. Nurick, M.D. Olson, J.R. Fagnan and A. Levin, Deformation and Tearing of blast-loaded stiffened square plates, International Journal of Impact Engineering 16 (1995), 273-291

[10] J.K. Paik and A.K. Thayamballi, Ultimate Limit States Design of Steel-Plated Structures, John Wiley and Sons Ltd., West Sussex, England, 2004

[11] K. Ramajeyathilagam and C.P. Vendhan, Deformation and rupture of thin rectangular plates subjected to underwater shock, International Journal of Impact Engineering 30 (2004), 699-719.

[12] N.S. Rudrapatna, R. Vaziri and M.D. Olson, Deformation and failure of blast-loaded square plates, International Journal of Impact Engineering 22 (1999), 449-467.

[13] J. Slater, G. Rude and G. Paulgaard, Experimental Study of Air-Backed and Water-Backed Targets During Near-Contact Explosions, DRDC Suffield Technical Report \# TR 2005-152, 2005.

[14] T. Wierzbicki, Petalling of plates under explosive and impact loading, International Journal of Impact Engineering 22 (1999), 935-954. 

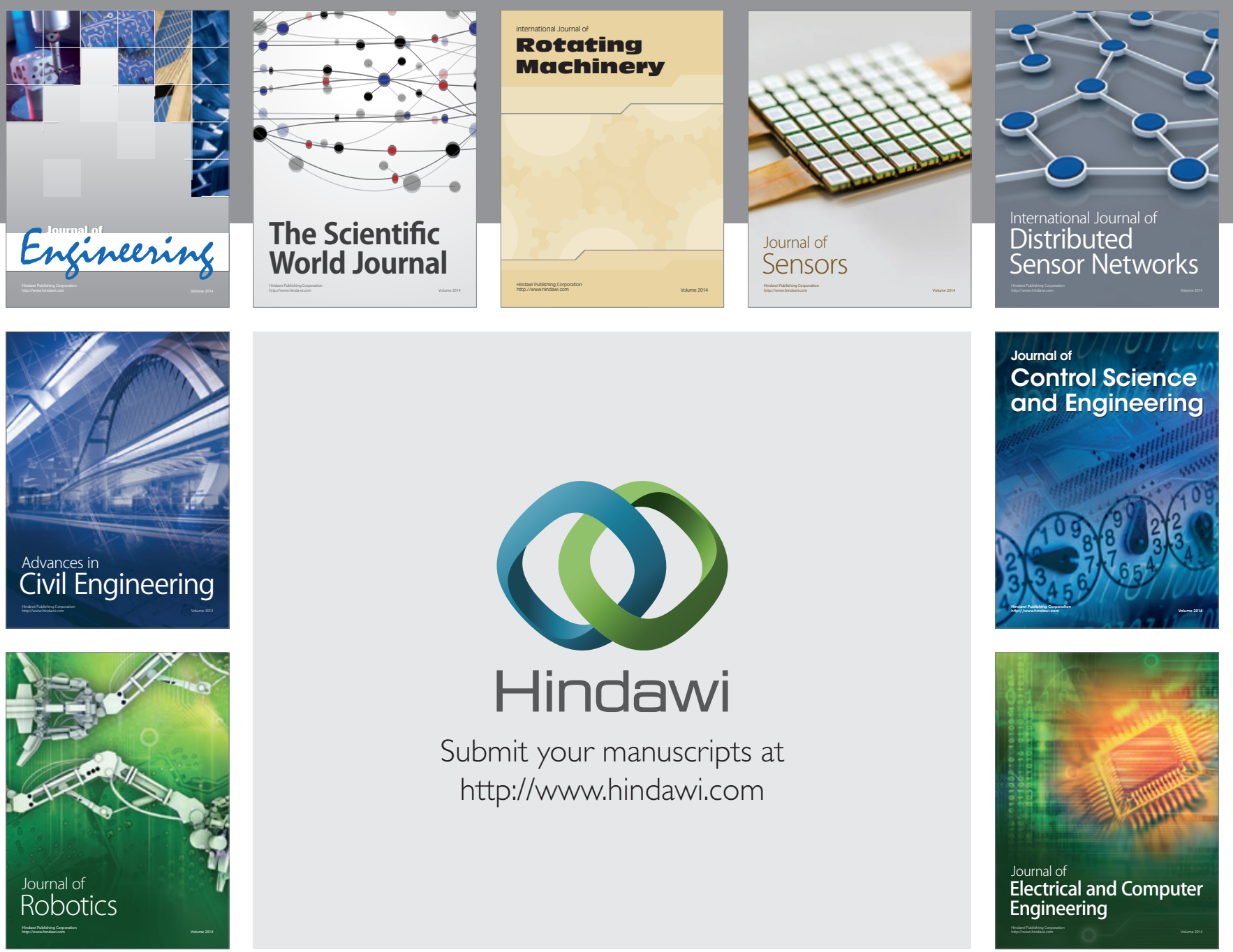

Submit your manuscripts at

http://www.hindawi.com
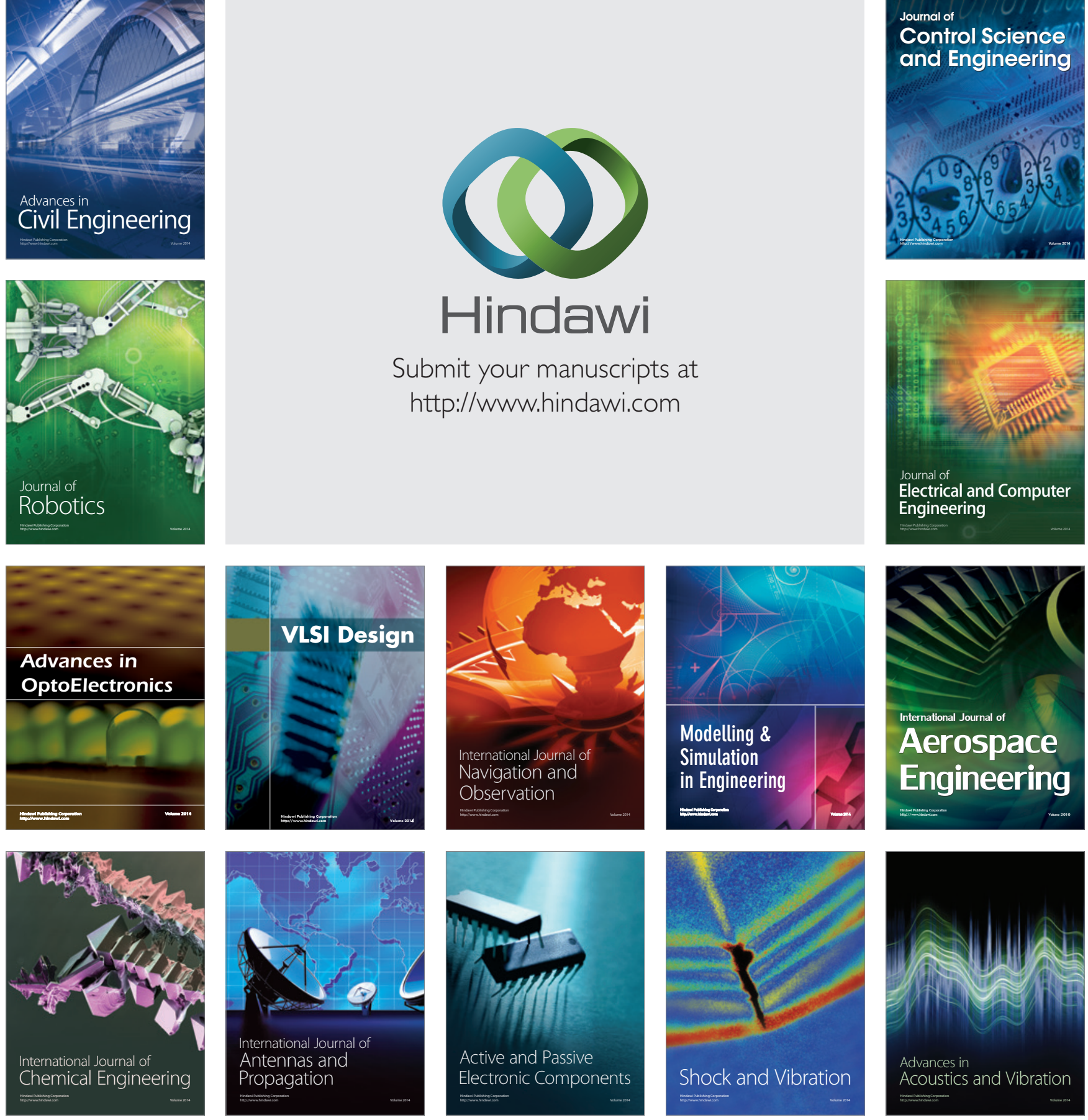